\title{
A randomised comparative study on intraoperative bispectral index monitoring vs. conventional monitoring on awakening time, extubatation time and early postoperative recovery from general anaesthesia using desflurane as inhalational anaesthetic during maintenance of anaesthesia in morbidly obese patients undergoing laparoscopic sleeve gastrectomy surgery
}

\author{
Krishna Murthy TK. ${ }^{1}$, Vinay Kumar PV.,** \\ ${ }^{\mathbf{1}}$ Associate Prfoessor, ${ }^{2}$ Assistant Professor, Dept. of Anaesthesia, Sri Sidhartha Medical College, Tumkur, Karnataka, India
}

Received: $20^{\text {th }}$ October, 2017

*Corresponding Author:

Email: drvinay81@gmail.com

\begin{abstract}
Introduction: In India incidence of obesity is in increasing trend. Anaesthetising morbidly obese patients is challenge to anaesthesiologist. Due to alteration in pharmacokinetics and pharmacodynamics in obese patients, drug dosing in these patients is different from patients with normal body mass index. This has led to lot of confusion in titration of anaesthetic drugs perioperatively. Any method which helps in perioperative drug titration may help in optimal intraoperative maintenance of anaesthesia, early awakening at the end of surgery and early postoperative recovery. We hypothesize that intraoperative Bispectral index (BIS) monitoring allows optimal titration of anaesthetic drugs intraoperatively and decrease awakening time, early postoperative recovery from general anaesthesia in morbidly obese patients undergoing laparoscopic laparoscopic sleeve gastrectomy surgery.

Materials and Methods: Two groups of 40 patients each were anaesthetized with the use of BIS monitoring in BIS- GROUP and in NON-BIS GROUP patients were anaesthetized without the using BIS monitoring. The heamodynamic parameters heart rate (HR) and mean arterial pressure (MAP) were recorded before induction, after induction at 1 minute $(\mathrm{min}), 3 \mathrm{~min}$, and $5 \mathrm{~min}$, after incision at $1 \mathrm{~min}$, $5 \mathrm{~min}, 10 \mathrm{~min}, 15 \mathrm{~min}, 30 \mathrm{~min}, 45 \mathrm{~min}, 60 \mathrm{~min}$, and $70 \mathrm{~min}$ were recorded. Awakening time (time to eye opening to verbal command) recorded every minute, time to extubation at $1 \mathrm{~min}, 5 \mathrm{~min}, 15 \mathrm{~min}$ were recorded and time to achieve Modified Aldrete score $\geq 9$ were recorded.

Results: Mean awakening time, time to extubate and Modified Aldrete score $\geq 9$ were significantly shorter in the BIS group as compared to the NON-BIS group $(\mathrm{P}<0.05)$. There were no statistical differences in intraoperative mean $\mathrm{HR}$ and mean MBP in both groups $(\mathrm{P}$ value $>0.05$ ).

Conclusion: Without compromising the hemodynamic stability BIS monitoring was effective in early awakening, associated with early postoperative recovery in morbidly obese patients undergoing laparoscopic laparoscopic sleeve gastrectomy surgery.
\end{abstract}

Keywords: Morbid obesity, Bispectral index, Recovery.

\section{Introduction}

Obesity itself is a concern for anaesthesiologist, usually associated with co-morbid conditions like hypertension, diabetes and accelerated atherosclerosis. Potential anaesthesia concerns in morbidly obese patients include patient positioning, difficult mask ventilation, intubation, perioperatively more frequent respiratory and cardiovascular events and altered pharmacokinetics and pharmacodynamics leading to delayed awakening and recovery from general anaesthesia. $^{1-3}$

Electroencephalographic monitors like bispectral index have shown better titration of anesthesia drugs during general anaesthesia. ${ }^{4,5}$ Bispectral index (BIS) monitoring has been proven to be effective in optimizing anaesthesia level, probably help in rapid awakening, shorten recovery time and reduce anaesthetic drug consumption. ${ }^{6,7}$ It would be advantage if BIS monitoring helps in more rapid awakening (emergence), early extubation and early postoperative recovery from general anaesthesia in morbidly obese patients. The aim of this randomized comparative study was to investigate the effect of intraoperative conventional monitoring plus BIS monitoring on awakening time, extubation time and postoperative recovery vs. conventional monitoring which includes heart rate, arterial blood pressure, electrocardiogram, oxygen saturation, temperature end tidal carbon dioxide and urine output in morbidly obese patients undergoing laparoscopic gastric mini bypass under general anaesthesia using desflurane inhalational anaesthetic during maintenance of anaesthesia.

\section{Materials and Methods}

After the ethical and scientific committee approval study was done on total 80 patients. Informed written consent was taken from each patient. Patients were randomized into two groups of 40 patients each by giving serial number, patients getting odd number were considered in B-GROUP, where patients anaesthetized with the use of BIS monitoring and patients getting even number were considered in C-GROUP, where patients were anaesthetized with only conventional monitors. Inclusion criteria include morbidly obese patients electively scheduled for laparoscopic sleeve gastrectomy surgery, adult patients of either gender aged 20-40 years and ASA II patients. Exclusion 
criteria include patients with history of neurological dysfunction and patients using psychotropic drugs.

As all the patients were considered full stomach, premedicated with pantoprazole $40 \mathrm{mg}$ orally on the night before surgery, and metechlopramide $10 \mathrm{mg}$ orally one hours before surgery with sips of water. On the day of surgery patient in preoperating room baseline vitals were recorded, all patients were preloaded with one litre Ringer lactate. Preoxygenated for 3 min with $100 \%$ oxygen. Induction with injection xylocord $1.5 \mathrm{mg} / \mathrm{kg}$, injection fentanyl $2 \mu / \mathrm{kg}$ and injection propofol 1.5 $2 \mathrm{mg} / \mathrm{kg}$ intravenously and intravenous rocuronium 0.9 $\mathrm{mg} / \mathrm{kg}$, was administered to facilitate tracheal intubation and neuromuscular blockade. Maintenance of anaesthesia with $40 \%$ oxygen mixed with air to maintain an end-tidal carbon dioxide concentration of 35-40mmHg.Intraoperative coventional monitoring was done with pulse oximetry, non-invasive blood pressure, electrocardiogram, end-tidal carbondioxide, nasopharyngeal temperature probe. In B-GROUP along with conventional monitoring BIS monitoring (BISA-2000 software 2.21, Aspect Medical Systems) was initiated at induction and smoothing time was 30 seconds. Desflurane 6\% in 2 liters/minute fresh gas flow mixed in air and oxygen was administered to all patients after endotracheal intubation, desflurane concentration was titrated by anaesthesiologist dependening on haemodynamic status [HR and MBP] in C-GROUP and B-GROUP desflurane concentration titrated to achieve a target BIS in the range of 40-60. Intravenous one gram paracetamol was given to all patients of both groups after induction of anesthesia and local infiltration with bupivacaine $0.25 \%$ was given to all skin incisions. Rocuronium $0.15 \mathrm{mg} / \mathrm{kg}$ neuromuscular blockade was maintained to a single twitch of train of four. After the procedure Desflurane was discontinued and fresh gas flows were increased to 10litres/min. Neuromuscular blockade was reversed with neostigmine $0.05 \mathrm{mg} / \mathrm{kg}$ and glycopyrrolate $0.015 \mathrm{mg} / \mathrm{kg}$ intravenously. A verbal command to open eyes was given every minute. After a train-of -four ratio 0.9 patients were extubate. Time from discontinuation of Desflurane to awakening times (eye opening on verbal commands), time to extubation and time to achieve aldrete score $\geq 9$ were recorded. After extubation patients were transferred to post anaesthetic care unit (PACU). Postoperative pain was treated with intravenous tramadol, fentanyl and ketorolac (multimodal analgesia).
The sample size of 80 was enough to maintain the power of study at least $80 \%$. All the continuous variables were assessed for the normality using SHAPIRO-WILK'S TEST. If the variables were normally distributed, they were expressed as Mean $\pm \mathrm{SD}$, otherwise Median (interquartile range). All the categorical variables were expressed either as percentage or proportions. Comparison of normally distributed continuous variables was done by either independent sample t-test or ANOVA based on the number of groups. Comparison of non-normally distributed continuous variables was being done by MANN-WHITNEY U TEST or KRUSKAL-WALLI'S $\mathrm{H}$ Test. Comparison of categorical variables was done by either CHI-SQUARE Test or FISHERS-EXACT Test based on the number of observations. Data entry was done in MS-EXCEL spread sheet. Data validation and analysis was carried out by SPSS VERSION 11.0.All the p-values $<0.05$ were considered as statistically significant.

\section{Results}

There was no statistically significant difference between B-Group and C-BIS Group in terms of age, sex, body weight and duration of surgery.

The mean HR and MAP was calculated for B and $\mathrm{C}$ groups at base line, induction, intubation at $1 \mathrm{~min}$, $3 \mathrm{~min}$ and $5 \mathrm{~min}$, at incision $1 \mathrm{~min}, 5 \mathrm{~min}, 10 \mathrm{~min}, 15$ min, $30 \mathrm{~min}, 45 \mathrm{~min}, 60 \mathrm{~min}, 75 \mathrm{~min}$, at closure, at extubation $1 \mathrm{~min}$, 5min, $15 \mathrm{~min}$. At all times there was no statistically significant difference between two groups in terms of mean HR and mean MAP. The mean HR was calculated for B and C group and was found to be $77.8 \pm 3.39$ and $79.1 \pm 3$.4. There was no statistically significant difference between two groups $(\mathrm{p}=0.095)$. The mean MAP for B and C group was found to be $94.5 \pm 3.5$ and $95.8 \pm 4.2$. There was no statistically significant difference between two groups $(\mathrm{P}=0.136)$.

The mean awakening time $(11.38 \pm 2.807$ vs. $14.92 \pm 3.885, \mathrm{p}$ value $=0.000$ ), mean extubation time $(15.90 \pm 2.863 \mathrm{vs} 19.28 \pm 4.120, \mathrm{p}$ value $=0.000)$ and mean time to achieve Modified Aldrete score were $(31.60 \pm 3.862 \mathrm{vs} 40.80 \pm 4.681, \mathrm{p}$ value $=0.000)$ found to be statistically significant. There was a statistically significant difference between the two groups in awakening time ( $\mathrm{p}$ value $=0.000)$, extubation time $(\mathrm{p}$ value $=0.000$ ) and Modified Aldrete score $\geq 9$ ( $p$ value $=0.000$ )

Table 1: Showing awakening time, extubation time and time to achieve aldrete score $\geq 9$ in min.

\begin{tabular}{|c|c|c|c|c|c|}
\hline 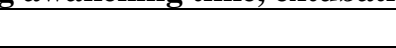 & Group & $\mathbf{N}$ & Mean & Std. Deviation & P-value \\
\hline \multirow{2}{*}{ Awakening Time } & BIS & 40 & 11.38 & 2.807 & \multirow{2}{*}{0.000} \\
\hline & Non BIS & 40 & 14.92 & 3.885 & \\
\hline \multirow{2}{*}{ Extubation Time } & BIS & 40 & 15.90 & 2.863 & \multirow{2}{*}{0.000} \\
\hline & Non BIS & 40 & 19.28 & 4.120 & \\
\hline \multirow{2}{*}{$\begin{array}{l}\text { Time to achive modified } \\
\text { aldrete score } \geq 9\end{array}$} & BIS & 40 & 31.60 & 3.862 & \multirow{2}{*}{0.000} \\
\hline & Non BIS & 40 & 40.80 & 4.681 & \\
\hline
\end{tabular}




\section{Discussion}

In our study we found that there were no statistical differences in intraoperative mean MBP and mean HR in both groups at all times. There were statistically significant difference in awakening time, extubation time and time to achieve modified aldrete score $\geq 9$. The present study had demonstrated that use of BIS monitoring led to early postoperative recovery of morbidly obese patients undergoing laparoscopic sleeve gastrectomy. The results were comparable to those reported in other studies that assessed titration of propofol $^{9}$ Desflurane or sevoflurane ${ }^{10}$ by using BIS monitoring. Song et $\mathrm{al}^{11}$ had concluded that BIS monitoring allows reduction in intraoperative anesthetic consumption and appears to decrease emergence time and recovery times. Heavner et $\mathrm{al}^{12}$ had demonstrated that BIS monitoring had improved recovery profiles in elderly patients anesthetized by desflurane and nitrous oxide. BOZTUG et $\mathrm{al}^{13}$ studied bispectral index monitoring in patients posted for craniotomy found be beneficial in terms of anaesthetic requirement. White et $\mathrm{al}^{14}$ found that Auditory Evoked Potential and bispectral index (BIS) monitoring can decrease the endtidal Desflurane concentration during maintenance of anesthesia. Use of cerebral monitors to minimize the intraoperative anesthetic drug consumption and improve the recovery process had raised concerns regarding deleterious effects of increased autonomic activity $^{15}$. However, in our study, intraoperative hemodynamic variables were not statistically significant. Limitations of our study were we did not consider pediatric patients, Blinding was not done, and age group is limited to $25-50$ years.

\section{Conclusions}

The use of bispectral index monitoring was effective in reducing the awakening time, extubation time and led to early postoperative recovery in morbidly obese patients posted for elective laparoscopic sleeve gastrectomy without compromising the heamodynamics.

\section{References}

1. Juvin P, Lavaut E, Dupont H, Lefevre P, Demetriou M, Dumoulin JL, et al. Difficult tracheal intubation is more common in obese than in leanpatients. AnesthAnalg 2003;97:595-600.

2. Chung F, Mezei G. Adverse outcomes in ambulatory anesthesia. Can J Anaesth 1999;46:R18-34.

3. Fisher A, Waterhouse TD, Adams AP. Obesity: Its relation to anaesthesia. Anaesthesia 1975;30:633-47.

4. Drover DR, Lemmens HJ, Pierce ET, Plourde G, Loyd G, Ornstein E, et al.Patient state index: Titration of delivery and recovery from propofol, alfentanil, and nitrous oxide anesthesia. Anesthesiology 2002;97:82-9.

5. Recart A, White PF, Wang A, Gasanova I, Byerky S, Jones SB. Effect of auditory evoked potential index monitoring on anesthetic drug requirements and recovery profile after laparoscopic surgery. Anesthesiology 2003;99:813-8.
6. Recart A, White PF, Wang A, Gasanova I, Byerky S, Jones SB. Effect of auditory evoked potential index monitoring on anesthetic drug requirements and recovery profile after laparoscopic surgery. Anesthesiology 2003;99:813-8.

7. Guignard B, Coste C, Menigaux C, Chauvin M. Reduced isoflurane consumption with bispectral index monitoring. Acta Anaesthesiol Scand2001;45:308-14.

8. Aldrete, JA. The post-anesthesia recovery score revisited. Journal of Clinial Anesthesia. 1995:7:89-91-1.

9. Liu N, Chazot T, Genty A, Landais A, Restoux A, McGee K, et al. Titration of propofol for anesthetic induction and maintenance guided by the bispectral index: Closed-loop versus manual control: A prospective, randomized, multicenter study. Anesthesiology 2006; 104:686-95.

10. Yli Hankala A, Vakkuri A, Annila P, Korttila K. EEG bispectral index monitoring in sevoflurane or propofol anaesthesia: Analysis of direct costs and immediate recovery. Acta Anaesthesiol Scand 1999;43:543-9.

11. Tamer H. Ibrahim, Gamal T. Yousef, Ali M. Ali Hasan, Hossam I. Eldesuky. Effect of bispectral index monitoring on desflurane consumption and recovery time in morbidly obese patients undergoing laparoscopic sleeve gastrectomy. Anesth Essays Res. 2013;7(1):89-93.

12. Heavner JE, Kaye AD, Lin BK, King T. Recovery of elderly patients from two or more hours of desflurane or sevoflurane anaesthesia. Br J Anaesth2003;91:502-6.

13. Burrow N, Bigat Z, Akyuz M, Demir S, Ertok E. Does using the bispectral index (BIS) during craniotomy affect the quality of recovery? J Neurosurg Anesthesiol. 2006;18(1):1-4

14. White PF, Ma H, Tang J, Wender RH, Sloninsky A, Kariger R. Does the use of electroencephalographic bispectral index or auditory evoked potential index Monitoring facilitate recovery after desflurane anesthesia in the ambulatory setting? Anesthesiology 2004;100:8117.

15. Drummond JC. Monitoring depth of anesthesia: With emphasis on the application of the Bispectral Index and the middle latency auditory evoked response to the prevention of recall. Anesthesiology 2000;93:876-82. 